\title{
Correction to: bronchopulmonary dysplasia: a predictive scoring system for very low birth weight infants. A diagnostic accuracy study with prospective data collection
}

\author{
Ikbel El Faleh ${ }^{1,2} \cdot$ Mohamed Faouzi $^{3} \cdot$ Mark Adams $^{4} \cdot$ Roland Gerull $^{5} \cdot$ Jamel Chnayna $^{1} \cdot$ Eric Giannoni $^{1}$. \\ Matthias Roth-Kleiner ${ }^{1}$ • for the Swiss Neonatal Network
}

(C) Author(s) 2021

\section{Correction to: European Journal of Pediatrics https://doi.org/10.1007/s00431-021-04045-8}

In the original published version of this article under the last paragraph of the Result section the author made changes on their presented data the corrected data are as follows [Bold text used to highlight problem area]:

\section{Results}

As an example, for a preterm infant born at 26 3/7 weeks PMA $\left(\mathrm{GA}^{*}=-2.81\right)$, with an incomplete course of antenatal corticoids (antenatal steroid** $=1$ ), a BW of $600 \mathrm{~g}\left(\mathrm{BW}^{*}=-6.33\right)$, with 3 days of $\mathrm{MV}\left(\mathrm{MV}^{*}=-0.035\right)$, who received surfactant (surfactant** $=1)$, was treated for PDA $\left(\mathrm{PDA}^{* *}=1\right)$ and had no proven infection (infection** $=0$ ), the score would be $\mathbf{0 . 7}$ and the risk of developing BPD28 would be $\mathbf{6 6 . 3 \%}$. If the score was calculated for the same patient 1 week later after an additional 7 days of MV, the score would increase to $\mathbf{1 . 6}$ and therefore the probability to develop BPD would be $\mathbf{8 3 \%}$. As another example, the BPD36 risk score for this same premature infant born with 3 days of $\mathrm{MV}\left(\mathrm{MV}^{*}=0.35\right)$, who received surfactant ( $\left.\operatorname{surfactant} t^{*}=1\right)$, and was treated for PDA $\left(\mathrm{PDA}^{* *}=1\right)$ without infection (infection** $=0$ ) would be -1.21 and the risk of developing BPD36 would be $22.89 \%$. This risk would increase to $48.65 \%$ if the duration of MV increased to 10 days.

The original article has been corrected.

The online version of the original article can be found at https://doi.org/ 10.1007/s00431-021-04045-8

\author{
Ikbel El Faleh \\ ikbel.el-faleh@chuv.ch \\ Mohamed Faouzi \\ Mohamed.Faouzi@unisante.ch \\ Mark Adams \\ Mark.Adams@usz.ch \\ Roland Gerull \\ Roland.Gerull@ukbb.ch \\ Jamel Chnayna \\ jamel.ch2010@gmail.com \\ Eric Giannoni \\ Eric.Gianonni@chuv.ch
}

Matthias Roth-Kleiner

Matthias.Roth@chuv.ch

1 Clinic of Neonatology, Department Women-Mother-Child, Lausanne University Hospital, University of Lausanne, Lausanne, Switzerland

2 Department of Paediatrics, Hospital Neuchâtel, Neuchâtel, Switzerland

3 Centre for Primary Care and Public Health (Unisanté), University of Lausanne, Lausanne, Switzerland

4 Department of Neonatology, University Hospital Zurich, University of Zurich, Zurich, Switzerland

5 Department of Neonatology, University Children's Hospital Basel, Basel, Switzerland 
Open Access This article is licensed under a Creative Commons Attribution 4.0 International License, which permits use, sharing, adaptation, distribution and reproduction in any medium or format, as long as you give appropriate credit to the original author(s) and the source, provide a link to the Creative Commons licence, and indicate if changes were made. The images or other third party material in this article are included in the article's Creative Commons licence, unless indicated otherwise in a credit line to the material. If material is not included in the article's Creative Commons licence and your intended use is not permitted by statutory regulation or exceeds the permitted use, you will need to obtain permission directly from the copyright holder. To view a copy of this licence, visit http://creativecommons.org/licenses/by/4.0/.

Publisher's note Springer Nature remains neutral with regard to jurisdictional claims in published maps and institutional affiliations. 